\title{
Abuso sexual na infância: compreensão a partir da Epidemiologia e dos Direitos Humanos
}

Ivan França Junior ${ }^{1}$

FRANÇA-JUNIOR, I. Child sexual abuse: a comprehensive approach based on Epidemiology and Human Rights, Interface - Comunic, Saúde, Educ, v.7, n.12, p.23-38, 2003.

This article examines the possibilities and limits of the epidemiological and human rights approaches to child sexual abuse (CSA). To this end, it examines epidemiological literature as to prevalence and risk factors and concludes that CSA occurs on a large scale, primarily affecting youths, especially girls; it is not occasional or isolated in the life of people and communities and its determinants are largely unknown. The article discusses the problems of this production and indicates possible reasons for its limitations. Analysis from the human rights standpoint included an examination of the intersubjective nature of the law and of the nature of the legal sphere (private or public) and the powers that determine the compliance of individuals with a given legal rule. From this angle, one concludes that the right to grow and to live free of sexual molestation during childhood is a right pertaining to freedom and integrity (private autonomy). There are explicit mechanisms in Brazil's laws forbidding such behavior, but they have little efficacy and do not effectively cover most of the population. The operating conditions of Brazilian law cause children to become socially vulnerable to CSA. The conclusions are that these approaches, although distinct, can complement each other, so as to foster intersectorial activity for the eradication of CSA.

KEY WORDS: Child sexual abuse; Epidemiology; Human Rights.

Este artigo examina as possibilidades e limites das abordagens epidemiológica e de direitos humanos da questão do abuso sexual na infância (ASI). Para tanto, examina-se a literatura epidemiológica sobre magnitude e fatores de risco, concluindo-se que o ASI é de grande magnitude; afeta principalmente jovens, em especial mulheres; não sendo episódico ou isolado nas vidas das pessoas e das comunidades e que seus determinantes são, em grande parte, desconhecidos. Discutem-se os problemas desta produção e indicam-se as razões possíveis para seus limites. A análise de direitos humanos compreendeu o exame do caráter intersubjetivo do direito, da natureza da esfera (privada ou pública) relativa ao direito e às forças que determinam a adesão de sujeitos a uma determinada norma jurídica. Nesta perspectiva, conclui-se que direito a viver e desenvolver-se livre do abuso sexual na infância é um direito da liberdade e integridade (autonomia privada). Há mecanismos explícitos na legislação nacional que vedam este comportamento, mas com baixa eficácia e cobertura populacional. As condições de operação do direito brasileiro fazem com que as crianças sejam socialmente vulneráveis ao ASI. Conclui-se que estas abordagens, embora distintas, podem ser usadas de modo complementar com vistas à ação intersetorial para a erradicação do ASI.

PALAVRAS-CHAVE: Maus-tratos sexuais infantis; Epidemiologia; Direitos Humanos.

\footnotetext{
${ }^{1}$ Departamento de Saúde Materno-Infantil, Faculdade de Saúde Pública - Universidade de São Paulo. <ifjunior@usp.br>
} 
O abuso sexual na infância parece ser prática bastante antiga, assim como as práticas de castigo e, até mesmo, eliminação física de crianças. Há polêmicas se o tratamento dispensado às crianças vem melhorando na contemporaneidade, mas, a tomar pelas regras jurídicas vigentes, é visível que esses comportamentos não são mais desejáveis (Minayo, 2002).

É preciso diferenciar, em uma perspectiva histórica e antropológica, as interações que se dão entre adultos e crianças, no tocante a contatos corporais, que são definidas por variadas normas culturais humanas. Segundo Scheper-Hughes (1998), há culturas em várias partes do mundo citando a Turquia, o Brasil rural e outros - nas quais o toque público dos genitais de bebês por determinados adultos (mães, pais e vizinhas) é admitido como natural e gracioso.

Essas normas culturais devem ser entendidas diferentemente daquelas que visam obtenção de prazer sexual dos adultos com uso de crianças, por meio da coerção privada com o uso da violência, posição hierárquica ou sedução. $O$ foco deste artigo recai nesta segunda situação e somente esta pode ser chamada de abuso.

No campo da Saúde, somente a partir do trabalho de Henry Kempe et al. (1962) a comunidade médico-sanitária começou a se deter sobre o problema. Entretanto, o modelo medicalizado proposto por Kempe, entendido como a formulação de uma condição social em termos médicos (sintomas, sinais, diagnóstico e tratamento), não possibilitou maiores progressos no que diz respeito a investigações e intervenções. De qualquer modo, no fim da década de 1960, todos os Estados dos EUA haviam estabelecido a notificação compulsória dos casos.

Da década de 1980 em diante, o abuso sexual na infância vai receber uma atenção mais intensa com a publicação de inúmeros trabalhos, com diferentes definições e abordagens, quase exclusivamente nos países desenvolvidos.

O texto que segue pretende ilustrar quais são os limites e possibilidades das abordagens que se baseiam nos discursos epidemiológicos e dos direitos humanos.

Na literatura científica, seja de origem médico-sanitária ou das Ciências Humanas, há uma grande variedade de definições sobre o que vem a ser abuso sexual na infância, que se refere tanto à delimitação dos comportamentos considerados abusivos como da faixa etária atingida.

As definições podem variar daquelas que aceitam como evidência a presença de dano ou elemento físico como lesões genito-anais ou presença de esperma, até as que incluem o exibicionismo.

Tem variado também o modo de abordar os entrevistados para a recuperação dos episódios abusivos. Holmes e Slap (1998), ao revisar 149 estudos de abuso de meninos, identificaram três modos básicos para a construção da ocorrência epidemiológica: no primeiro ( $48 \%$ dos casos), não era possível identificar qual a abordagem utilizada, seja em estudos com dados originais ou a partir de registros secundários de agências de proteção à criança; no segundo ( $27 \%$ e chamado de subjetivo pelos autores), os entrevistados eram questionados sobre abuso, vitimização ou 'assalto' sexual, mas deixavam a estes a definição dos termos; e no terceiro caso 
( $25 \%$ e chamado de objetivo), os entrevistados eram igualmente questionados, mas a definição destes termos partia dos pesquisadores mediante perguntas sobre comportamentos explicitados pelo entrevistado (situações de exibicionismo, toques, tentativa de intercurso sexual, entre outros).

Estas várias definições $e$ modos de perguntar têm redundado em diferentes estimativas da ocorrência populacional assim como de seus determinantes nos vários estudos.

Para os propósitos deste artigo, consideraremos abuso sexual na infância a utilização de crianças por adultos, familiares ou não, para a sua satisfação sexual e que pode tomar a forma de exposição (exibicionismo ou a visão de atos sexuais ou pornografia), molestação (toque de genitais) ou relações sexuais (oral, vaginal ou anal; com ou sem uso de força). A detecção da ocorrência poderá ter sido feita por relato de suas vítimas ou agressores ou por algum tipo de evidência clínica. Esta definição tende a englobar um maior número de situações.

\section{Abordagem epidemiológica}

A análise epidemiológica de risco avalia a associação entre fatores individuais (tanto da criança quanto do perpetrador do abuso), familiares e/ou ecológicos/contextuais com o evento de interesse. Tem o potencial de estimar a magnitude de um problema de saúde, suas determinações, bem como indicar grupos populacionais que podem ser priorizados na alocação de cuidados à saúde e outras ações de potencial impacto. Estes fatores de risco podem ser considerados como preditores ou como "causas", dependendo das características do estudo epidemiológico.

Assim, do ponto de vista epidemiológico, o abuso sexual de crianças pode ser analisado como evento causado/previsto por outros fatores - Risco de ser abusado ou de ser abusador sexualmente - ou como causa/preditor de outras doenças - $O$ abuso sexual como risco para a saúde - (Vanderven Er Newberger, 1994). Na primeira situação, o abuso é considerado como desfecho (variável dependente) e outras variáveis como potenciais fatores de risco ou proteção (variáveis independentes ou explanatórias).

$\mathrm{Na}$ segunda situação, o abuso sexual é considerado como fator de risco para um conjunto de situações de sofrimento ou adoecimento na vida infantil ou, até mesmo, adulta. Para esta abordagem, há farta literatura indicando repercussões na saúde física e mental das crianças que podem ser duradouras.

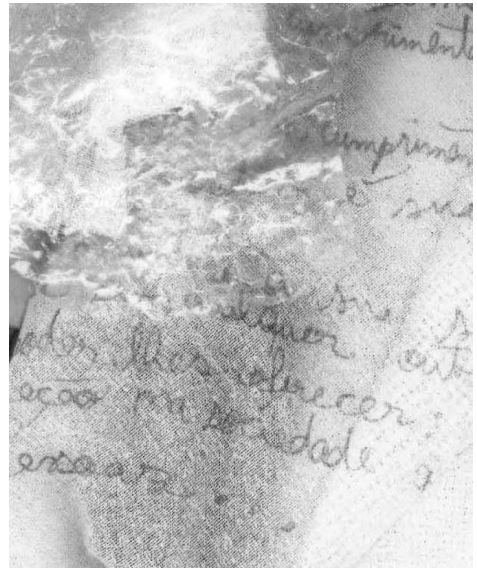

A ênfase deste artigo recai sobre a primeira - o risco de ser abusado.

\section{A magnitude do problema}

As prevalências têm variado de 3 a $16 \%$ para homens e 2 a $62 \%$ para mulheres (Finkelhor, 1994). Finkelhor acredita que uma estatísticasíntese, para o conjunto de 19 estudos analisados, seria de $20 \%$ para mulheres e 5 a $10 \%$ para homens. Na tabela 1 são apresentadas prevalências de países selecionados. Mesmo havendo países com valores menores, chama a atenção que o fenômeno é muito mais freqüente do que se pode pensar inicialmente. 
FRANÇA-JUNIOR, I.

Tabela 1 Prevalência de abuso sexual na infância em países selecionados segundo sexo, idade na entrevista e ano de publicação

\begin{tabular}{|c|c|c|c|c|}
\hline \multirow[t]{2}{*}{ País } & \multicolumn{2}{|c|}{ Prevalência (\%) } & \multirow{2}{*}{$\begin{array}{l}\text { Idade na } \\
\text { entrevista }\end{array}$} & \multirow{2}{*}{$\begin{array}{l}\text { Ano do } \\
\text { estudo }\end{array}$} \\
\hline & Fem & lasc & & \\
\hline Canadá & 18 & 8 & adultos & 1983 \\
\hline República Dominicana & \multicolumn{2}{|c|}{33} & universitários & 1985 \\
\hline Noruega & 17,2 & 0,9 & 12-15 & 1987 \\
\hline Bélgica & 19 & - & adultas & 1987 \\
\hline EUA & 27 & 16 & adultos & 1990 \\
\hline Costa Rica & 32 & 13 & universitários & 1991 \\
\hline Finlândia & $6-8$ & $1-3$ & 15 & 1994 \\
\hline Espanha & 22 & 15 & adultos & 1995 \\
\hline Ontário - Canadá & 12,8 & 4,3 & adultos & 1997 \\
\hline Queensland- Austrália & 39 & 13 & adultos & 1997 \\
\hline
\end{tabular}

Fontes: Finkelhor, 1994; Goldman \& Padayachi, 1997.

É notável a existência de poucos estudos no Brasil sobre esta temática. Esta lacuna faz com que desconheçamos a proporção de crianças afetadas pelo abuso, bem como os fatores associados a sua ocorrência.

Uma fonte de dados disponível refere-se às informações coletadas nos serviços que atendem crianças nesta situação como a Associação Brasileira Multiprofissional de Proteção à Infância e à Adolescência (ABRAPIA), o Programa de Atenção à Vítima de Abuso Sexual (PAVAS), o Centro Regional de Atenção aos Maus Tratos na Infância de Campinas (CRAMI-Campinas), o Centro Regional de Atenção aos Maus Tratos na Infância do ABCD (CRAMI$A B C D)$ e o Centro de Estudos e Atendimento Relativos ao Abuso Sexual (CEARAS), entre outros. A detecção de casos, por parte dos serviços, depende de um grande número de fatores, tais como presença e gravidade de lesões resultantes do abuso, circunstâncias familiares e comunitárias que bloqueiem a comunicação, visibilidade da instituição e a sensibilidade de profissionais de saúde e educação para a detecção de abusos, entre outros.

A utilização científica de dados dos serviços é restrita, pois estes provavelmente permitam examinar a ponta do "iceberg", já que a literatura internacional indica que somente $3 \%$ dos casos são reportados (Leventhal, 1998).

Recentemente, foi realizado um estudo transversal, com amostras representativas de mulheres de 15 a 49 anos na cidade de São Paulo (SP) e Zona da Mata de Pernambuco (PE), acerca da saúde e violência contra mulher (Schraiber et al., 2002). Foram entrevistadas 1.172 (SP) e 1.474 mulheres (PE). As mulheres foram indagadas face a face sobre a ocorrência deste evento com base em uma definição internacionalmente padronizada pela OMS e de um modo acolhedor e compreensivo. Na entrevista, identificou-se uma prevalência de 7,8\%, em SP, e em PE, de 5,8\%.

Além de se buscar conhecer as prevalências, procurou-se avaliar a dificuldade de informar sobre violência sexual. Para isto, foi solicitado que as mulheres preenchessem cédulas anônimas com faces tristes e alegres para indicar, respectivamente, a ocorrência ou não da violência, depositando-as 


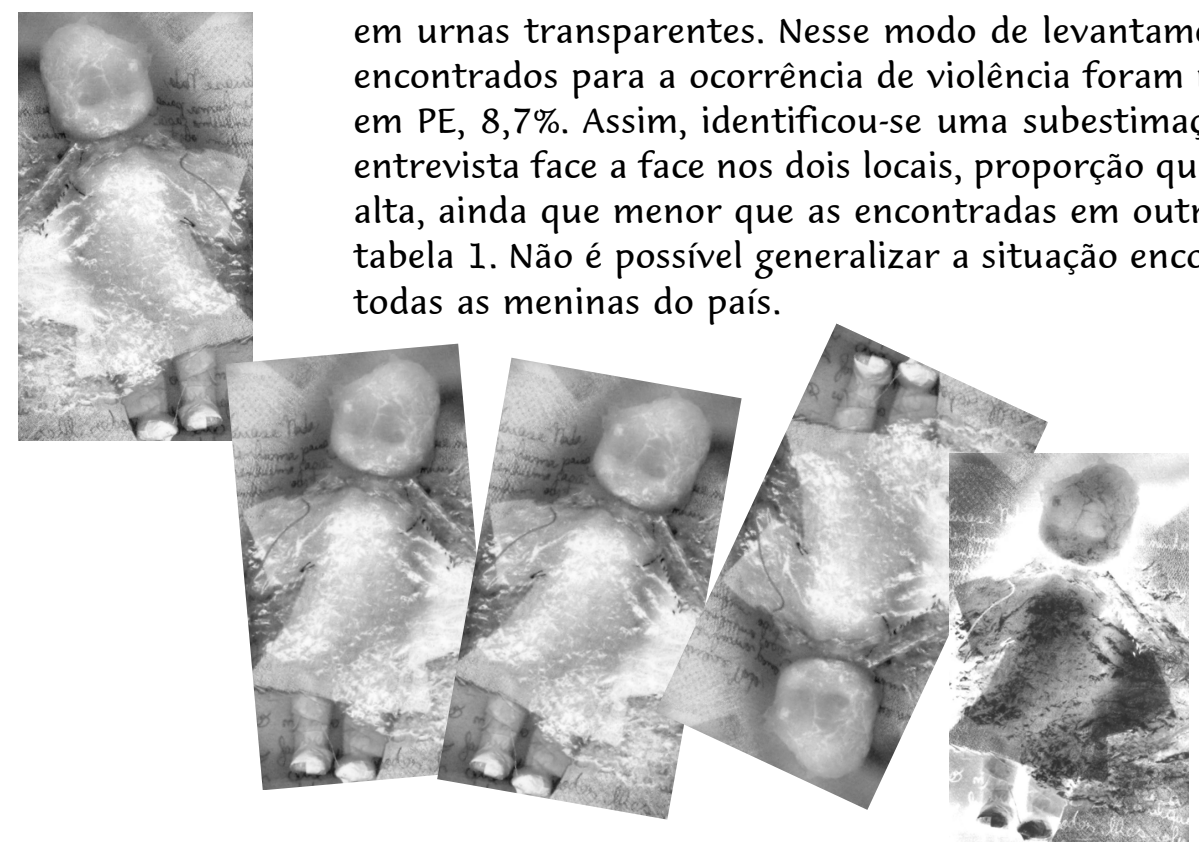

Fatores de risco

Poucos estudos pretendem identificar fatores preditores ou causais que possam indicar ações para populações em risco. Para este artigo, consideraremos a literatura disponível somente para os riscos associados a maior probabilidade de ser abusado na infância.

Diferentemente do observado para outras formas de maus-tratos (negligência ou violência física), não tem sido comum a investigação, em grande profundidade, dos fatores associados à ocorrência de abuso sexual. Finkelhor (1994) resume os fatores de risco em dois grandes grupos: os que diminuem a quantidade e a qualidade do cuidado infantil por parte dos pais; e os que produzem crianças vulneráveis, carentes emocionalmente. No entanto, estes fatores não foram plena e adequadamente operacionalizados em estudos epidemiológicos.

Em um estudo em Ontario (Canadá), em que foram entrevistadas 9.953 pessoas com 15 anos ou mais em um inquérito domiciliar, foram detectadas prevalências de menor magnitude, de 12,8\% entre mulheres e de 4,3\% entre homens (MacMillan et al., 1997). Para casos severos de abuso sexual (ameaça de relações sexuais, toque em genitais e tentativa ou consumação de ato sexual), foram encontradas prevalências de $11,1 \%$ e 3,9\% entre mulheres e homens, respectivamente, indicando situação grave, pois teríamos uma proporção de casos severos dentre os casos totais. Neste estudo, a idade dos meninos não esteve associada com maior ocorrência ou gravidade, mas entre meninas quanto maior a idade menores as chances de ocorrência e gravidade.

No estudo finlandês, as idades mais acometidas foram de 12 a 16 anos, mas dos nove aos dez anos houve proporções consideráveis (Sariola, 1994). O estudo espanhol, por sua vez, identificou que $15 \%$ dos homens e $22 \%$ das mulheres foram abusados antes dos 18 anos de idade (López et al., 1995). A maior ocorrência de abuso entre os meninos na Espanha foi atribuída 
pelos autores ao grande número de egressos de escolas religiosas. $\mathrm{Na}$ Austrália, as prevalências têm distribuição similar ao estudo espanhol, com grande proporção nas crianças mais jovens. Contudo, as diferenças na distribuição dentro da infância não foram estatisticamente significativas, não configurando idade como um bom indicador de risco para abuso (Goldman E Padayachi, 1997).

Quanto ao número de abusos reportados pelos indivíduos, chama a atenção que o abuso tende a se repetir em uma proporção considerável. $\mathrm{Na}$ Noruega (Pedersen \& Aas, 1995), por exemplo, dos quatro aos 12 anos, $66,6 \%$ dos afetados experienciaram três ou mais episódios: na Espanha $40 \%$ dos adultos entrevistados relataram de dois ou mais episódios na infância.

No tocante à análise dos determinantes do abuso sexual, alguns poucos fatores têm sido identificados. Em estudo longitudinal, na Nova Zelândia, com uma amostra de mil crianças seguidas do nascimento até 16 anos de idade, encontrou-se uma prevalência global de $10,4 \%$ (17,3\% e 3,4\% para meninas e meninos, respectivamente). Os fatores identificados foram: a) ser menina; b) famílias com altos níveis de conflito conjugal; c) relatos de pouca ligação parental; d) relatos de superproteção paterna; e) relatos de problemas com álcool ou alcoolismo dos pais. Estes fatores conseguiram predizer apenas $10 \%$ da variância observada (Fergusson et al., 1996), com baixo poder preditivo ou fracos para serem pensados numa perspectiva causal.

Outros estudos identificaram como fatores de risco: a) meninas que vivem com padrastos ao invés de seus pais genéticos; b) crianças com problemas de desenvolvimento (atrasos ou deficiências) quando comparadas com crianças normais (Leventhal, 1998).

O maior número de casos são atribuídos a homens que pertencem à família (tios, primos, avôs), indicando que as maiores chances de ocorrência estão no âmbito familiar. No estudo de Schraiber et al. (2002), entre 40 a $50 \%$ dos casos de abuso de meninas foram atribuídos a homens da família, que não pais ou padrastos, para a Zona da Mata de Pernambuco e a cidade de São Paulo, respectivamente.

O nível educacional ou pertencimento a estratos socioeconômicos mais baixos dos pais, e o tamanho da família (número de crianças no domicílio), variáveis tradicionalmente associadas a inúmeras condições de saúde da criança, não se têm mostrado associados nas análises sobre abuso sexual.

Possibilidades e limites da abordagem epidemiológica A abordagem epidemiológica tem, como vimos, a vantagem de estimar a magnitude de um problema de saúde, indicando para os formuladores de políticas a quantidade de recursos que deveriam ser alocados para se alcançar uma cobertura adequada.

A Epidemiologia contribui ainda para o exame dos determinantes de eventos de saúde ou relacionados, apontando os grupos populacionais que devem ser priorizados na alocação de cuidados à saúde e fornecendo estimativas para avaliações de impacto. Estes fatores de risco podem ser considerados como preditores ou como "causas" variando, assim, a pretensão de impacto epidemiológico. Os fatores são aferidos pelas medidas 
de risco, quantificando a associação entre fatores individuais (tanto da criança quanto do perpetrador do abuso), familiares e/ou ecológicos/ contextuais com o evento da saúde de interesse.

Os estudos epidemiológicos, sinteticamente, indicam que o abuso sexual na infância:

1 é de grande magnitude;

2 afeta principalmente jovens, em especial mulheres;

3 não se trata de fenômeno episódico ou isolado nas vidas das pessoas $e$ das comunidades;

4 tem seus determinantes, em grande parte, desconhecidos.

Como vimos, no que diz respeito aos determinantes do abuso sexual na infância, a abordagem epidemiológica é ainda incipiente, tendo dificuldade para identificar fatores associados ao abuso sexual que pudessem oferecer alternativas de prevenção. Uma primeira explicação para esta incapacidade está no fato de que foram poucos os estudos bem delineados realizados até o momento, nacional ou internacionalmente. Assim, predominam estudos transversais ou com pretensões descritivas e que podem ter vieses importantes.

Outro limite importante para a abordagem epidemiológica do abuso sexual na infância pode estar na própria racionalidade da Epidemiologia. Como sabemos, esta área opera, estocasticamente, por comparações das ocorrências entre grupos (expostos e não-expostos versus casos e não-casos) para, a partir da sua distribuição, avaliar as eventuais associações estatísticas entre fatores de exposição/causa e os desfechos.

Contudo, se o evento (desfecho ou exposição a risco) é muito disseminado, dificilmente conseguiremos grupos claramente distintos. Esta pode ser a situação do abuso sexual na infância, em que nos defrontamos com práticas sexuais bastante disseminadas - o uso de crianças para satisfação sexual privada e coercitiva dos adultos.

Como dizia um sábio epidemiologista inglês,
se todas as pessoas fumassem vinte cigarros por dia, os estudos clínicos de caso-controle assim como os de coorte nos levariam a concluir que o câncer de pulmão é uma enfermidade genética; e, em certo sentido, isto seria verdade dado que se todos estão expostos ao agente necessário, a distribuição de casos depende totalmente da suscetibilidade individual. (Rose, 1985, p.32)

Uma distribuição tão ampla, como a do abuso sexual na infância, que não se restringe a grupos sociais $e$ econômicos, pode significar que há questões culturais muito profundas que determinam sua ocorrência. A Epidemiologia contemporânea precisa aprofundar sua reflexão conceitual e metodológica, alimentando sua imaginação a partir das contribuições de outros saberes, para poder examinar os caminhos por onde passam os determinantes do abuso sexual na infância.

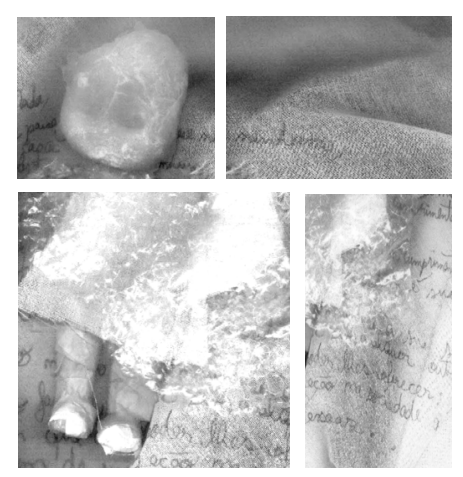




\section{Abordagem de Direitos Humanos}

A pandemia de HIV/Aids trouxe para o campo da Saúde um conjunto de desafios e também de novas perspectivas para análise, implementação $e$ avaliação de intervenções. Uma das grandes novidades foi o surgimento do conceito de vulnerabilidade, formulado originalmente por Mann et al. (1992).

Embora ainda mais concentrada na epidemia de AIDS, esta abordagem vem se estendendo para outras questões e contextos.

Este conceito indica que precisamos levar em consideração outros aspectos além dos comportamentos individuais, usualmente traduzidos em fatores de risco pela epidemiologia. Deste modo, para analisarmos um determinado problema de saúde, é preciso avaliar três planos interdependentes que se articulam para determinar este problema: individual, programático e social. Esses planos podem ser constituídos a partir dos conhecimentos produzidos pelos mais diferentes saberes científicos, com suas abordagens qualitativas $e$ quantitativas. Limites e possibilidades desta estratégia são detalhados $e$ discutidos por Ayres (2002).

No tocante ao plano social da análise da vulnerabilidade, Mann et al. (1992) desenvolveram duas propostas não antagônicas, mas que implicam horizontes $e$ racionalidades distintas. No primeiro livro, os autores propuseram um escore baseado em oito indicadores do Programa de Desenvolvimento das Nações Unidas (PNUD). O segundo livro não trabalha mais com esses indicadores $e$ remete à avaliação da vulnerabilidade para a esfera dos Direitos Humanos (Mann \& Tarantola, 1996). Se para a primeira propunha-se uma métrica social, política e econômica, na segunda busca-se a avaliação de como os sujeitos de direito em relação, em uma sociedade determinada, têm seus direitos humanos respeitados ou violados.

A avaliação do abuso sexual na infância, do ponto de vista dos Direitos Humanos, deve considerar que esta é uma questão social com repercussões na saúde e que pode ser realizada por variados ângulos com base em abordagens metodológicas diversificadas. Como alertam Mann e Tarantola (1996), trata-se de uma nova linguagem para o campo da Saúde que demandará muitos esforços para serem incorporados seus conceitos, regras e procedimentos.

Ressaltaremos neste artigo alguns aspectos centrais que a racionalidade dos Direitos Humanos nos colocam à disposição, a saber: o caráter intersubjetivo de um dado direito, a natureza da esfera (privada ou pública) atinente a um determinado direito $e$ as forças opostas da facticidade/validade para a adesão a uma determinada norma jurídica.

Na perspectiva habermasiana, abraçada aqui, os direitos são, acima de tudo, relacionais:

\footnotetext{
Um direito, finalmente, não é nem uma arma nem as ações de um só homem. São uma relação e uma prática sociais, e em ambas os aspectos essenciais são a conectividade. Direitos são proposições públicas, envolvendo obrigações para com os outros assim como entitlements contra eles. (Michelmann apud Habermas, 1997, p.121)
}

Os direitos pressupõem o reconhecimento recíproco de prerrogativas e deveres dos indivíduos como membros livres e 


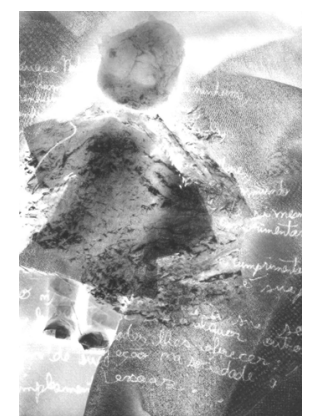

iguais em certa comunidade. Há sempre, desse modo, um sentido intersubjetivo nessa entre os parceiros do direito. Pretender o reconhecimento de um direito para si mesmo pressupõe o reconhecimento simétrico deste direito para com o outro. Do contrário, seria desejar um privilégio.

Por aí se entende o aforismo que diz ninguém pode alegar o desconhecimento da lei ao cometer crime, delito ou infração. Ao fazer parte, como cidadão, de uma comunidade jurídica, a pessoa reconhece seus direitos e deveres recíprocos para com os demais sujeitos. Em caso de conflito de interesses, o poder judiciário poderá ser acionado para dirimir eventuais conflitos que sujeitos não consigam privadamente. $O$ recurso à força não pode ser usado entre os sujeitos, pois está monopolizado no Estado.

No caso do abuso sexual, o discurso jurídico nacional e internacional dos Direitos Humanos, expresso em inúmeros documentos, rechaça a prática do abuso sexual na infância ao afirmar que as crianças têm direito à integridade física e mental. Ao definir esta integridade como direito, os Estados passam a ter
o dever de adotar todas as medidas legislativas, administrativas, sociais e educacionais apropriadas para proteger a criança contra todas as formas de violência física e mental, abuso ou tratamento negligente, maus-tratos ou exploração, inclusive abuso sexual, enquanto estiver sob custódia dos pais, do representante legal ou de qualquer outra pessoa responsável por ela" (Biblioteca Virtual de Direitos Humanos da Universidade de São Paulo, BVDH-USP, 2002).

É importante ressaltar que o Estado assume como sua tarefa proteger a criança até mesmo contra seus familiares e outros agentes, públicos ou privados. Assim, todos os sujeitos, incluído o próprio Estado, devem se abster de ações que possam violar o direito das crianças - sujeitos de direito integrais perante a lei - de viverem e se desenvolverem livres do abuso sexual.

Cabe também examinar a qual esfera de autonomia se refere o direito reconhecido para as crianças de ter preservada sua integridade física $e$ mental.

O discurso dos Direitos Humanos busca integrar a tradição dos direitos subjetivos com os mais recentes direitos sociais. Direitos subjetivos correspondem à liberdade de ação do indivíduo, sendo aqueles que "estabelecem os limites no interior dos quais um sujeito está justificado a empregar livremente a sua vontade. E eles definem liberdades de ação iguais para todos os indivíduos ou pessoas jurídicas, tidas como portadoras de direitos" (Siebeneichler, 1999, p.113). São direitos negativos, protegem indivíduos de outros indivíduos, empresas ou o Estado de sofrerem interferências tidas como ilícitas na sua liberdade, vida ou propriedade. Criam, assim, uma esfera de autonomia privada, protegendo a livre iniciativa de indivíduos singulares. Este conjunto de direitos "traduzem o princípio do direito moderno, segundo o qual é permitido tudo aquilo que não é proibido" (Siebeneichler, 1999, p.163).

$\mathrm{Na}$ tradição do Direito formal positivo esses direitos subjetivos visavam 


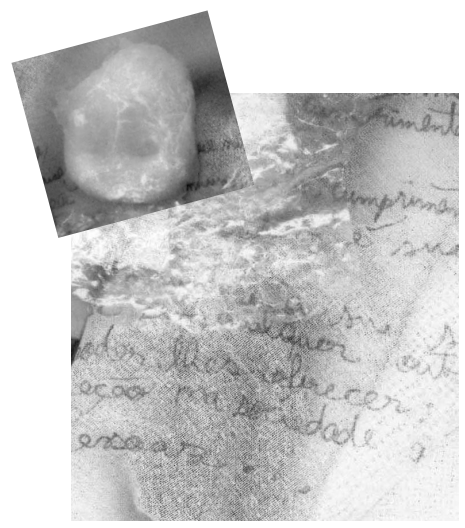

fundamentalmente à liberdade de fechar contratos e de dispor da propriedade privada (aquisição, herança ou venda). Claro está que, originariamente, esses direitos remetiam a uma liberdade de inspiração fortemente burguesa do século XVIII.

No entanto, contemporaneamente, os direitos subjetivos conformam um repertório importante para todos os grupos sociais, pois prevêem a proteção, $o$ respeito e a efetivação de direitos individuais, tais como o direito à vida; a não ser discriminado; a não ser torturado ou receber tratamento ou punição cruel, desumano ou degradante; a não ser escravizado; à não retroatividade de ofensas criminais; a ser reconhecido como pessoa perante a lei $e$ à liberdade de pensamento, consciência e religião. A Convenção dos Direitos Civis e Políticos da ONU de 1966 exprime este repertório, que deve ser alvo de atenção do campo da Saúde, pois os individuais têm sido o grupo de direitos mais negligenciados, quando não violados (BVDH-USP, 2002a).

Durante os séculos XIX e XX emergiram os chamados direitos sociais, que têm história mais recente do que os direitos subjetivos, vinculados às lutas políticas de setores democráticos e populares. Esses direitos estão modernamente codificados na Convenção Internacional sobre os Direitos Econômicos, Sociais e Culturais de 1966 da ONU (BVDH-USP, 2002b). Referem-se à garantia das condições para o pleno exercício público dos indivíduos. São direitos fundamentais para que alguém possa participar ativa e livremente, como cidadão, de uma comunidade jurídica. Os direitos à educação, ao trabalho e à saúde figuram entres eles. São também chamados direitos positivos ou de segunda geração e pressupõem iniciativas concretas do Estado para a sua garantia. O seu conjunto está relacionado à autonomia pública dos cidadãos ou à soberania do povo, nas palavras de Habermas.

Considerando esses elementos, podemos afirmar que o direito a não ser abusado sexualmente é um direito subjetivo, um direito à liberdade, pelo qual se espera que os demais sujeitos abstenham-se de atos que possam violar a integridade física e corporal de crianças. Poderíamos igualmente afirmar que o direito a não ser abusado sexualmente é um direito inderrogável - não pode ser suspenso por nenhum motivo - de não ser submetido a tratamento cruel, desumano ou degradante, conforme expresso no Artigo $7^{\circ}$ do Pacto Internacional dos Direitos Civis e Políticos de 1966 (BVDH-USP, 2002a).

Contudo, resta uma pergunta. Como garantir que os indivíduos, grupos sociais e instituições sigam essas normas jurídicas que buscam erradicar o abuso sexual?

Segundo Habermas (1997), a integração social não-violenta de sociedades complexas implica a coordenação dos planos de ação de vários atores, de tal modo que todos partilhem o entrelaçamento, o menos conflituoso possível, de intenções e ações. Para tal coordenação, a linguagem é imprescindível pois está voltada para o entendimento entre os sujeitos. Ainda segundo este autor, a linguagem jurídica procura acomodar as tensões oriundas de forças opostas da adesão a uma norma jurídica: a facticidade (coação de sanções 
exteriores) e a validade (força ligadora de convicções racionalmente motivadas).

Alguns sujeitos, destinatários da lei que afirma um direito, podem tomála apenas como ordens que restringem seu campo de ação (sua autonomia privada) e podem elaborar modos de fugir de sua aplicação, de contorná-la ou, até mesmo, de violá-la. Esses sujeitos baseiam-se no agir estratégico e a força fática da lei vem se contrapor a este comportamento. Outros podem assumir um enfoque performativo perante a lei, isto é, procuram considerar a validade desses mandamentos jurídicos e, assim, buscam ajustar, comunicacionalmente, suas ações (Habermas, 1997). Qualquer sujeito, ao discordar da lei, poderá recorrer a expedientes políticos e jurídicos de luta democrática para vê-la modificada ou revogada.

No tocante ao abuso sexual no Brasil, há inúmeros dispositivos legais na Constituição (artigo 27, parágrafo $4^{\circ}$.), no Código Penal (artigos 214 e 233) e no Estatuto da Criança e do Adolescente (artigos 252-257, 245) que visam garantir a coerção fática ao estabelecer sanções, penas no jargão jurídico, como reclusões, detenções e multas. Com vistas a garantir esses direitos, vêm sendo criadas, no Brasil, as varas especializadas e exclusivas da infância e juventude bem como organismos não jurisdicionais como os Conselhos Tutelares.

As situações de abuso sexual na infância que chegam às Varas da Infância tendem a ser apenadas. Contudo, chegam para o exame da justiça a minoria dos casos, aqueles mais severos, com evidências médico-legais ou perpetrados por estranhos.

No que se refere aos aspectos da validade da interdição do abuso sexual na infância, ainda é preciso que venhamos a desenvolver um conjunto de estratégias que visem fortalecer as convicções racionais rumo ao entendimento de que o abuso sexual na infância deve ser banido.

No Brasil, algumas iniciativas têm sido desenvolvidas, como as campanhas "Uma Vida sem violência é um direito nosso", do UNICEF e Ministério da Justiça, $e$ as campanhas desenvolvidas pela Comissão de Direitos Humanos da Câmara Federal. A partir de 2000, o dia 18 de maio foi instituído como o Dia Nacional do Combate ao Abuso e Exploração Sexual InfantoJuvenil (Lei Federal 9.970). Neste dia, várias atividades são desenvolvidas em todo o país.

Vale destacar que, em junho de 2000, foi realizada uma reunião, em que foi formulado um Plano Nacional de Enfrentamento da Violência Sexual Contra Crianças e Adolescentes, envolvendo participantes governamentais do Executivo federal, estadual $e$ municipal; do poder Legislativo federal e estadual, do poder Judiciário, especialmente da Justiça da Infância e Adolescência; do Ministério Público federal e estadual, da Defensoria Pública; das Polícias Federal, Civil e Militar; dos Conselhos Municipais, Estaduais e Nacional dos Direitos da Criança e do Adolescente, dos Conselhos Tutelares; dos organismos internacionais de cooperação técnica e financeira; do End Child Prostitution, Child Pornography and Trafficking in Children (ECPAT-Brasil), das organizações da sociedade civil e de representantes de Jovens. O documento final, conhecido como Carta de Natal, prevê objetivos que envolvem a pesquisa 
sobre a problemática, o provimento de assistência especializada, estabelecimento de medidas para a erradicação desta forma de violência, $e$ fortalecimento do sistema de defesa e responsabilização e do protagonismo juvenil (Recria, 2002).

Este plano é muito novo para ser avaliado, mas seu processo de definição permite, nos termos de Habermas, a criação de uma formação discursiva da opinião e da vontade perante o abuso. Assim, damos os primeiros passos mais consistentes para o enfrentamento da situação.

A efetivação desses direitos, por meio de políticas públicas, é que vai demonstrar a força dos poderes - fáticos e válidos - para garantir a vigência da norma jurídica do direito à integridade física e corporal das crianças.

Considerando o número de casos evidenciados por Schraiber et al. (2002) para as meninas, podemos afirmar que o Estado brasileiro, no momento, é carente de suficientes poderes fático e válido para fazer valer a interdição do abuso sexual de crianças.
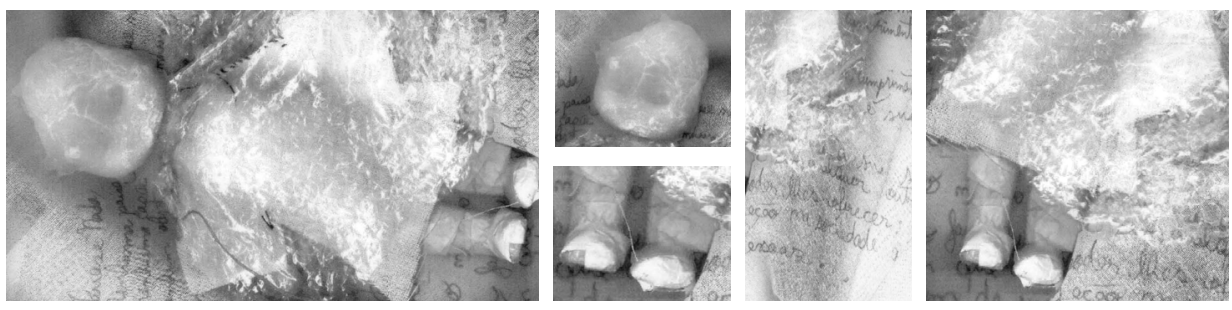

Possibilidades e limites da abordagem de Direitos Humanos Uma possibilidade particularmente especial do discurso dos Direitos Humanos é seu caráter universalizante, na medida em que atribuir um direito a um grupo de pessoas implica assumir que todos devem gozar tal direito. Esta racionalidade contrasta com a racionalidade probabilística da Epidemiologia, em que os expostos serão alvos prioritários da ação por apresentarem excessos de eventos estatisticamente significativos. A perspectiva dos Direitos Humanos tem, deste modo, a potencialidade de a todos incluir, independentemente de maior ou menor chance. Contudo, esta universalidade deve ser conquistada cotidianamente (Bobbio, 1992).

Conforme nos mostra Habermas (1997), esta racionalidade não está baseada em nenhuma moralidade ou normatividade infalível e ideal. Sendo de natureza procedimental, não se baseia sobre o conteúdo íntimo de uma norma jurídica, mas no processo democrático que a cria e implementa. Segundo o autor, a legitimidade do direito está apoiada em um arranjo comunicativo: "enquanto participantes de discursos racionais, os parceiros do direito devem poder examinar se uma norma controvertida encontra ou poderia encontrar o assentimento de todos os possíveis atingidos (Habermas, 1997, p.113).

O procedimento democrático, por sua vez, não é prática natural nem previamente formulada. Cada sociedade concreta - comunidade jurídica persegue seus caminhos para novas ordenações intersubjetivas. Assim, as democracias dependem da existência de sociedades civis complexas e de esferas públicas intactas que tenham capacidade de influenciar, ao canalizar 
os fluxos das liberdades comunicativas dos cidadãos, os sistemas políticos $e$ jurídicos (Siebeneichler, 1999).

Esta dependência dos processos democráticos e jurídicos por parte do Direito é crucial para o sucesso ou fracasso da reivindicação e para promulgação de um direito até sua efetivação. Para sua plena consecução $e$ gozo, é preciso interferir na elaboração, formulação e implementação dos direitos que queremos ver consubstanciados.

Nos termos de Bobbio (1992, p.5),

os direitos do homem, por mais fundamentais que sejam, são direitos históricos, ou seja, nascidos em certas circunstâncias, caracterizadas por lutas em defesa de novas liberdades contra velhos poderes, e nascidos de modo gradual, não todos de uma vez e nem de uma vez por todas.

No caso brasileiro, temos uma experiência democrática ainda pouco aprofundada, em que o Direito - como sistema de saber e ação - ainda se encontra relativamente pouco permeável. Os cidadãos brasileiros - incluídas as crianças - são vulneráveis socialmente ao abuso físico e sexual.

Para viver livre do abuso sexual no Brasil, configura-se o dilema apontado por Bobbio (1992, p.10),
... uma coisa é proclamar este direito, outra é desfrutá-lo efetivamente. A linguagem dos direitos humanos tem indubitavelmente uma grande função prática, que é emprestar' uma força particular às reivindicações dos movimentos que demandam para si e para os outros a satisfação de carecimentos materiais e morais, mas ela se torna enganadora se obscurecer ou ocultar a diferença entre o direito reivindicado e o direito reconhecido e protegido.

Assim, no tocante ao abuso sexual na infância, o reconhecimento do direito das crianças viverem livres desta violência ainda está por consubstanciar-se em prática social no Brasil.

\section{Conclusão}

A despeito de basearem-se em racionalidades distintas, as abordagens epidemiológica e de Direitos Humanos podem ser trabalhadas como complementares, ampliando as possibilidades de alianças $e$ ações intersetoriais que incidam sobre o grave problema do abuso sexual na infância. A Epidemiologia pode favorecer a compreensão da dinâmica populacional, suas causas ou preditores deste fenômeno social e coletivo, enquanto a linguagem dos Direitos Humanos pode favorecer a crença partilhada intersubjetivamente - razões e comportamentos individuais e coletivos - que considera válida a interdição do abuso sexual. 
FRANÇA-JUNIOR, I.

\section{Referências}

ABRAPIA. Associação Brasileira Multiprofissional de Proteção à infância e à adolescência. Disponível em $<$ http://www.abrapia.org.br>. acesso em 25 set. 2002.

AYRES, J.R.C.M. Do processo de trabalho em saúde à dialógica do cuidado: repensando conceitos e práticas em saúde coletiva. São Paulo, 2002. Tese (Livre-Docência), Faculdade de Medicina, Universidade de São Paulo.

BOBBIO, N. A era dos direitos. Rio de Janeiro: Campus, 1992.

BVDH/USP. Biblioteca Virtual de Direitos Humanos da USP. Convenção sobre os Direitos da Criança artigo 19, inciso 1 de 1990. Disponível em <http://www.direitoshumanos.usp.br/documentos/tratados/ crianca/convencao_sobre_o_direitos_da_crianca.html>. acesso em 25 set. 2002.

BVDH/USP. Biblioteca Virtual de Direitos Humanos da USP. Convenção dos Direitos Civis e Políticos da ONU. Disponível em <http://www.direitoshumanos.usp.br/documentos/tratados/internacionais/ pacto_internacional_dos_direitos_civis_e_politicos.html>. acesso em 25 set. 2002a.

BVDH/USP. Biblioteca Virtual de Direitos Humanos da USP. Convenção Internacional sobre os Direitos Econômicos, Sociais e Culturais da ONU. Disponível em <http:// www.direitoshumanos.usp.br/documentos/tratados/internacionais>. acesso em 25 set. 2002b.

CEARAS. Centro de Estudos e Atendimento Relativos ao Abuso Sexual. Disponível em <http:// www.usp.br/servicos/cearas/cearhopa.html>. acesso em 25 set. 2002.

CRAMI. Centro Regional de Atenção aos Maus-tratos na Infância. Disponível em <http:// www.crami.org.br>. acesso em 25 set. 2002.

FERGUSSON, D.M., LYNSKEY, M.T., HORWOOD, L.J. Childhood sexual abuse and psychiatric disorder in young adulthood: I. Prevalence of sexual abuse and factors associated with sexual abuse. J Am Acad Child Adolesc Psychiatry, v.35, p.1355-64, 1996.

FINKELHOR, D. The international epidemiology of child sexual abuse. Child Abuse \& Neglect, v.18, p.409-17, 1994

FINKELHOR, D., HOTALING, G., LEWIS, I.A., SMITH, C. Sexual abuse in a national survey of adult men and women: prevalence, characteristics, and risk factors. Child Abuse Negl., v.14, p.19-28, 1990.

GOLDMAN, J.D.G., PADAYACHI, U.K. The prevalence and nature of child sexual abuse in Queensland, Australia. Child Abuse Negl., v.21, p.489-498, 1997.

HABERMAS, J. Direito e Democracia: entre facticidade e validade. Rio de Janeiro: Tempo Universitário 1997. v.1.

HOLMES, W.C., SLAP, G.B. Sexual abuse of boys. J. Am. Med. Assoc., v.280, p.1855-62, 1998.

KEMPE, C.H., SILVERMAN, F.N., STEELE, B.F., DROEGEMUELLER, W., SILVER, H.K. The battered child syndrome. J. Am. Med. Assoc., v.181, p.17-24,1962.

LEVENTHAL, J.M. Epidemiology of sexual abuse of children: old problems, new directions. Child Abuse Negl., v.22, p.481-91, 1998.

LÓPEZ, F., CARPINTERO, E., HERNÁNDEZ, A., MARTÍN, M.J.D., FUERTES, A. Prevalencia y consecuencias del abuso sexual al menor en España. Child Abuse Negl., v.19, p.1039-50, 1995.

MACMILLAN, H.L., FLEMING, J.E., TROCME, N., BOYLE, M.H., WONG, M., RACINE, Y.A., BEARDSLEE, W.R., OFFORD, D.R. Prevalence of child physical and sexual abuse in the community. Results from the Ontario Health Supplement. J. Am. Med. Assoc., v.278, p.131-5, 1997. 
MANN, J., TARANTOLA, D.J.M. AIDS in the world II. New York: Oxford University Press, 1996.

MANN, J., TARANTOLA, D.J.M., NETTER, T.W. AIDS in the world. Cambridge: Harvard University Press, 1992.

MINAYO, M.C.S. O significado social e para a saúde da violência contra crianças e adolescentes. In: WESTPHAL, M.F. Violência e criança. São Paulo: EDUSP, 2002. p.95-114.

PEDERSEN, W., AAS, H. Sexual victimization in Norwegian children and adolescents: victims, offenders, assaults. Scand. J. Soc. Med., v.23, p.173-8, 1995.

RECRIA. Rede de Informações sobre Violência Sexual contra Crianças e Adolescentes. .Disponível em <http://www.cecria.org.br/Página\%20da\%20RECRIA/www.cecria.org.br-recria/DBDADOS/ INDEX.HTM>. acesso em 25 set. 2002.

ROSE, G. Sick individuals and sick populations. Int. J. Epidemiol., v.14, p.32-8, 1985.

SARIOLA, H. The prevalence of child sexual abuse in Finland. Child Abuse Negl., v.18, p.827-35, 1994.

SCHEPER-HUGHES, N. Institutionalized sex abuse and the catholic church In: SCHEPER-HUGHES, N., SARGENT, C. (Eds.) Small wars: the cultural politics of childhood. Berkely: University of California Press, 1998. p.295-317.

SCHRAIBER, L.B., D'OLIVEIRA, A.F.L., FRANÇA-JR, I., DINIZ, S.G., PORTELLA, A.P., LUDERMIR, A.B., COUTO, M.T., VALENÇA, O. Visibilidade/invisibilidade no estudo epidemiológico do abuso sexual contra meninas na cidade de São Paulo e Zona da Mata de Pernambuco. In: CONGRESSO BRASILEIRO DE EPIDEMIOLOGIA, 5, 2002. Curitiba. Anais... Curitiba, 2002.

SIEBENEICHLER, F.B. Uma filosofia do direito procedimental. Tempo Bras., v.138, p.153-72, 1999.

VAnderven, A.M., NeWBergeR, E.H. Child abuse. Ann. Rev. Public Health, v.15, p.367-79, 1994.

FRANÇA-JUNIOR, I. Abuso sexual infantil: los abordajes Epidemiológico y de los Derechos Humanos, Interface - Comunic, Saúde, Educ, v.7, n.12, p.23-38, 2003.

Este artículo examina las posibilidades y los límites de los abordajes epidemiológico y de derechos humanos sobre el abuso sexual en la infancia (ASI). Para eso, se examina la literatura epidemiológica acerca de la magnitud y los factores del riesgo. Se concluye que el ASI es de gran magnitud; afecta principalmente jóvenes, en especial mujeres; no es episódico ni aislado en la vida de las personas y de las comunidades y sus determinantes, en gran parte, son desconocidos. Se discuten los problemas de este abordaje y se indican las razones posibles para sus límites. El análisis de los derechos humanos abarcó el examen del carácter intersubjetivo del derecho, la naturaleza de la esfera (privada o pública) en que el derecho está inscrito y las fuerzas (facticidad/validad) que gobiernan la adhesión de un sujeto a una norma legal determinada. En esta perspectiva, se concluye que ese derecho de vivir y desarrollarse libre del abuso sexual en la infancia es un derecho de la libertad y de la integridad personal (autonomía privada).

Hay mecanismos explícitos en la legislación nacional que sellan esta conducta, pero con pequeña cobertura y baja eficacia poblacional. Las condiciones de la operación del sistema judicial brasileño hacen que los niños sean socialmente vulnerables al ASI. Concluye que estos abordajes, aunque con racionalidades distintas, pueden ser usados de la manera complementaria para acciones intersectoriales.

PALABRAS CLAVE: Abuso sexual infantil; Epidemiologia; Derechos Humanos. 
FRANÇA-JUNIOR, I.

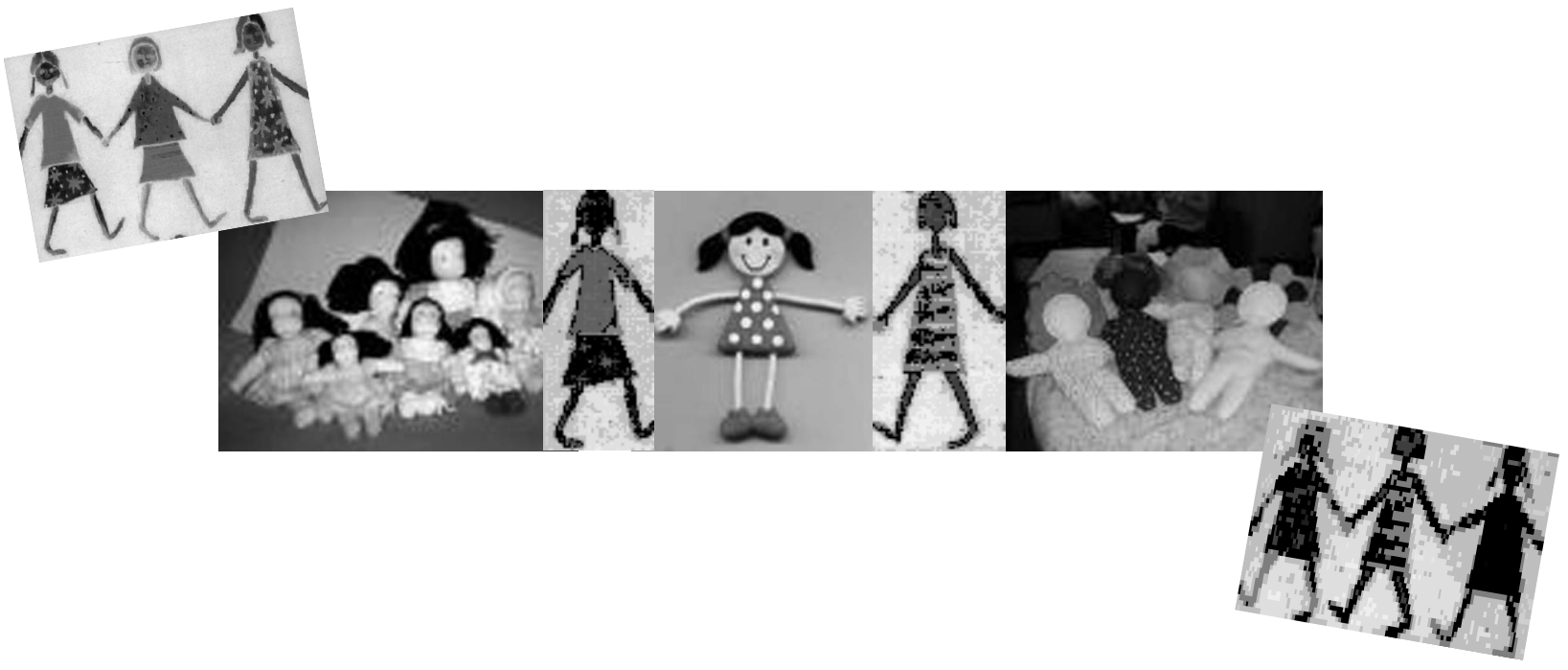

38 Interface - Comunic, Saúde, Educ, v7, n12, p.23-38, fev 2003 